\title{
Prospectively defined murine mesenchymal stem cells inhibit Klebsiella pneumoniae-induced acute lung injury and improve pneumonia survival
}

Holger Hackstein ${ }^{*}$, Anne Lippitsch', Philipp Krug ${ }^{1}$, Inna Schevtschenko', Sabine Kranz ${ }^{1}$, Matthias Hecker², Kristina Dietert ${ }^{3}$, Achim D. Gruber $^{3}$, Gregor Bein ${ }^{1}$, Cornelia Brendel ${ }^{4}$ and Nelli Baal ${ }^{1}$

\begin{abstract}
Background: Numerous studies have described the immunosuppressive capacity of mesenchymal stem cells (MSC) but these studies use mixtures of heterogeneous progenitor cells for in vitro expansion. Recently, multipotent MSC have been prospectively identified in murine bone marrow (BM) on the basis of PDFGRa ${ }^{+}$SCA $1^{+} \mathrm{CD}^{2} 5^{-}$TER1 $19^{-}$(PaS) expression but the immunomodulatory capacity of these MSC is unknown.

Methods: We isolated PaS MSC by high-purity FACS sorting of murine BM and after in vitro expansion we analyzed the in vivo immunomodulatory activity during acute pneumonia. PaS MSC $\left(1 \times 10^{6}\right)$ were applied intratracheally $4 \mathrm{~h}$ after acute respiratory Klebsiella pneumoniae induced infection.

Results: PaS MSC treatment resulted in significantly reduced alveolitis and protein leakage in comparison to mock-treated controls. PaS MSC-treated mice exhibited significantly reduced alveolar TNF-a and IL-12p70 expression, while IL-10 expression was unaffected. Dissection of respiratory dendritic cell (DC) subsets by multiparameter flow cytometry revealed significantly reduced lung DC infiltration and significantly reduced CD86 costimulatory expression on lung CD103 ${ }^{+}$DC in PaS MSC-treated mice. In the post-acute phase of pneumonia, PaS MSC-treated animals exhibited significantly reduced respiratory $\mathrm{LL}-17^{+} \mathrm{CD} 4^{+} \mathrm{T}$ cells and IFN- $\gamma^{+} \mathrm{CD} 4^{+} \mathrm{T}$ cells. Moreover, PaS MSC treatment significantly improved overall pneumonia survival and did not increase bacterial load.
\end{abstract}

Conclusion: In this study we demonstrated for the first time the feasibility and in vivo immunomodulatory capacity of prospectively defined MSC in pneumonia.

Keywords: Pneumonia, Mesenchymal stem cells, Klebsiella pneumonia, Acute lung injury

\section{Background}

The use of surface markers, such as CD34 for the prospective identification and isolation of hematopoietic stem cells (HSC) has fundamentally improved the clinical development and standardization of stem cell transplantation [1-3]. In contrast, most, if not all knowledge regarding the immunosuppressive capacity of mesenchymal stem cells (MSC) derives from studies using starting

\footnotetext{
* Correspondence: Holger.Hackstein@immunologie.med.uni-giessen.de ${ }^{1}$ Institute for Clinical Immunology and Transfusion Medicine, Universities of Giessen and Marburg Lung Center (UGMLC), Member of the German Center for Lung Research (DZL), University Hospital Giessen und Marburg, Justus-Liebig-University Giessen, Langhansstr. 7, D-35390 Giessen, Germany Full list of author information is available at the end of the article
}

cultures of mixed cell populations $[4,5]$. Therefore, the International Society for Cellular Therapy has published criteria for the definition of in vitro expanded heterogeneous MSC including positivity for CD73, CD90 and CD105, negativity for hematopoietic surfaces markers and other parameters [6]. Although these criteria are helpful to facilitate the comparison of heterogeneous MSC cultures, the prospective identification and direct isolation of homogenous MSC populations on the basis of surface markers will improve the standardization, comparability and reproducibility of MSC research.

Morikawa et al. has recently identified surface markers for the prospective identification of purified murine multipotent 
MSC from adult BM $[7,8]$. Their results suggested that the co-expression of Platelet-derived growth factor receptor $\alpha$ (PDFGR $\alpha, \mathrm{CD} 140 \mathrm{a})$ and stem-cell antigen 1 (Sca-1) on CD45 and TER119 negative BM cells effectively identifies primary MSC and these were termed double positive $\mathrm{PDFGRa}^{+} \mathrm{SCA}^{+} \mathrm{CD}^{+} 5^{-} \mathrm{TER}_{11}{ }^{-}(\mathrm{P} \alpha \mathrm{S}) \mathrm{MSC}$ [7]. P $\alpha \mathrm{S}$ MSC exhibited the highest numbers of colonies in a colony-forming unit-fibroblasts (CFU-F) assay and represented the only BM subset yielding MSC typical fibroblast/spindle-shaped cells. Only $\mathrm{P} \alpha \mathrm{S}$ cultures demonstrated a potent multilineage differentiation capacity into adipogenic, chondrogenic and osteogenic lineages indicating a high enrichment for MSC [7].

Heterogeneous results have been reported with regard to the immunosuppressive capacity of MSC [9, 10]. With respect to $\mathrm{T}$ cells, different pathways have been suggested including the direct inhibition of $\mathrm{T}$ effector cell proliferation and promotion of regulatory T cells [5]. Similarly, MSC have been suggested to inhibit the cytotoxicity of NK cells and $\mathrm{CD}^{+} \mathrm{T}$ lymphocytes $[11,12]$. With respect to dendritic cells (DC), MSC inhibit the monocyte-derived DC differentiation and suppress the costimulatory molecule expression, the pro-inflammatory cytokines IL12p70 and TNF- $\alpha$ as well as the priming of responder T cells $[5,13,14]$.

However, an increasing number of reports indicate that MSC are not immunosuppressive by themselves but can also exert immunostimulatory activity. For instance, Waterman et al. suggested that MSC can be polarized in immunosuppressive MSC1 or pro-inflammatory MSC2 by TLR3 and TLR4 triggering [15]. Moreover, some groups have reported accelerated heart allograft rejection and a failure to inhibit graft-versus-host disease after MSC treatment $[16,17]$. Potential mechanisms of immunostimulatory MSC may be related to the release of activatory exosomes or CCL2 production.

With respect to these heterogeneous immunological results and the increasing number of MSC studies suggesting therapeutic activity in acute pneumonia [18-20] the objective of this study was to investigate the in vivo immunomodulatory capacity of prospectively defined MSC in an animal model of gram negative pneumonia. Furthermore, to address more precisely the impact of this treatment on respiratory cellular inflammation we have used multiparameter flow cytometry allowing the dissection of key respiratory leukocyte subsets after MSC therapy [21-23].

\section{Methods}

Mice, Klebsiella pneumoniae infection and MSC treatment Specific-pathogen-free C57BL/6 (C57BL/6NCrl) and B6.Cg$\mathrm{Tg}$ (TcraTcrb)425Cbn/J mice (20-25 g each) were purchased from Charles River, Germany and maintained under specific-pathogen-free conditions. The mice were infected intratracheally with $3.5 \times 10^{5} \mathrm{CFU}$ of Klebsiella pneumoniae (K. pneumoniae) serotype 2 (American Type Culture
Collection (ATCC) 43816) in $50 \mu \mathrm{l}$ sterile $0.9 \% \mathrm{NaCl}$ as previously described [23]. Four hours p.i. the anesthetized mice received $1 \times 10^{6}$ washed $\mathrm{P} \alpha \mathrm{S} \mathrm{MSC}$ in $50 \mu \mathrm{l} 0.9 \% \mathrm{NaCl}$ intratracheally and were analyzed at the indicated time points (KpN/MSC). The control mice were treated identically but received $50 \mu \mathrm{l} 0.9 \% \mathrm{NaCl}(\mathrm{KpN} / \mathrm{NaCl})$. Some mice received $1 \times 10^{6}$ washed mouse lung fibroblasts (MLg;ATCC CCL-206) in $50 \mu \mathrm{l} 0.9 \% \mathrm{NaCl}$ and were indicated as such (KpN/MLg). Experiments were approved by the regional animal authority board (\#75/2011).

\section{BM preparation, PaS MSC sorting and in vitro expansion}

Femura and tibiae were prepared as previously described with minor modifications [7]. The bone fragments were collected and digested for $1 \mathrm{~h}$ at $37^{\circ} \mathrm{C}$ in alpha-MEM with L-Glutamine (PAN Biotech, Germany), $10 \%$ FBS (PAA, Germany), $1 \%$ penicillin/streptomycin (PAN Biotech) containing 3.92 U/ml collagenase (Wako Chemicals, Japan), $10 \mathrm{mM}$ Hepes (Gibco, Germany) and $3 \mathrm{mM} \mathrm{CaCl} 2$. The cell suspension was filtered through a $70 \mu \mathrm{m}$ cell strainer (BD Falcon, Germany) and collected by centrifugation at $400 \mathrm{~g}$ for $5 \mathrm{~min}$ at $4{ }^{\circ} \mathrm{C}$. Red blood cells were lysed using $155 \mathrm{mM} \mathrm{NH} \mathrm{NH}_{4} \mathrm{Cl} / 10 \mathrm{mM} \mathrm{KHCO}_{3}$ buffer ( $\mathrm{pH}$ 7.4) and washed with HBSS (PAN Biotech, Germany). After digestion, leucocytes were depleted with CD45 magnetic beads (Miltenyi Biotech, Germany) and stained with fluorochrome-labelled monoclonal antibodies and sorted by a BD ARIAIII cell sorter (Becton Dickinson, San Jose, CA, USA). P $\alpha$ S MSC were defined as positive for CD140a and Sca-1 and negative for CD45 and TER119 and were expanded in PureCoat Amine plates/flasks (BD, Germany) in alpha-MEM medium supplemented with L-Glutamine, $5 \%$ FBS (mesenchymal stem cell-qualified, Life technologies, Germany), and $5 \%$ human platelet lysate. Medium was changed every 3-7 days depending on cell growth. Human platelet lysate was prepared as previously described [24].

\section{Lung preparation}

Lung single cell suspensions (lung homogenates) were prepared after enzymatic digestion as previously described in detail [23]. In brief, the mice were euthanized and the lungs were perfused via the right ventricle with HBSS (PAA, Germany) to remove the intravascular pool of cells. The tissues were minced and digestion was performed in $0.09 \mathrm{U} / \mathrm{ml}$ type A collagenase (Roche, Germany) and 9.09 $\mathrm{U} / \mathrm{ml}$ DNase (Roche, Germany) in IMDM (PAA, Germany) with $10 \%$ FCS (PAA, Germany) at $37{ }^{\circ} \mathrm{C}$ for $1 \mathrm{~h}$. The single cell suspensions were prepared by tissue resuspension with $20 \mathrm{G} 1 \frac{1}{2}$ cannulas $(0.9 \times 40 \mathrm{~mm}$; BD, Germany) and by mashing through a $70 \mu \mathrm{M}$ cell strainer (BD, Germany). Red blood cells were lysed by ammonium chloride lysis. The cells were washed with HBSS for flow cytometry staining, or the leukocytes were magnetic-bead sorted after washing with $\mathrm{PBS} / 2 \% \mathrm{BSA} / 2 \mathrm{mM}$ EDTA 
(PAA, Germany). Bronchoalveolar lavages (BAL) were performed as previously described [25]. The bacterial load in lung homogenates and BAL were defined by preparing a two-fold dilution series in sterile HBSS after centrifugation $\left(2500 \mathrm{~g}, 15 \mathrm{~min}, 4^{\circ} \mathrm{C}\right.$ ) according to the method developed by Schott [26].

\section{Flow cytometry}

Cellular phenotyping and sorting were performed on a BD ARIAIII cell sorter (Becton Dickinson, San Jose, CA, USA). The following fluorochrome-labelled mAbs conjugated to FITC, PE, PeCy7, PerCPCy5.5, APC, APC-Cy7, Brilliant Violet 510, Brilliant Violet 605, Pacific Blue and Alexa700 or appropriate isotype controls were used for cell surface staining: CD11b, CD11c, CD45 (clone 30F1), CD86, CD103, CD140a (clone APA5), CD274 (PDL1), MHC-class II (I-A $\left.{ }^{\mathrm{b}}\right), \mathrm{GR}-1, \mathrm{~F} 4 / 80$, NK1.1, SCA-1 (clone D7), Siglec-F (BD Biosciences, Germany), TER119 and 120G8 (Dendritics, France). The surface staining time was $30 \mathrm{~min}$ on ice and cells were washed with staining buffer ( $1 \times$ HBSS, PAA, Germany) at $400 \mathrm{~g}$ for $5 \mathrm{~min}$ at room temperature (RT) before analysis. The number of acquired events was $\geq 500,000$.

The viability of sorted cells was $>90 \%$ as indicated by Sytox blue (Life Technologies, Germany) staining. All mAbs were ordered from Biolegend, Germany unless indicated otherwise. Absolute cell counts were determined with AccuCount Fluorescent Particles $7.7 \mu \mathrm{m}$ (Spherotech, Lake Forest, USA).

\section{CD4 T cell proliferation assay}

CD4+ T cells were isolated from the spleens of OT-II mice (B6.Cg- $\mathrm{Tg}$ (TcraTcrb) $425 \mathrm{Cbn} / \mathrm{J}$ ) using the $\mathrm{CD} 4+\mathrm{T}$ Cell Isolation Kit (Miltenyi Biotec, Germany). CD4+ T cells were labeled with $0,5 \mu \mathrm{M}$ CFSE (eBioscience, Germany) for $15 \mathrm{~min}$ at $37{ }^{\circ} \mathrm{C}$ with frequent agitation, then washed before being used in proliferation assays. DC were generated from C57BL/6 BM hematopoietic stem cells by culturing for 7 days in $10 \mathrm{ng} / \mathrm{ml}$ murine GM-CSF and $10 \mathrm{ng} / \mathrm{ml}$ murine IL-4 as previously described [27]. CD4+ T-cells $\left(1 \times 10^{5}\right)$ were cultured with DC $\left(1 \times 10^{4}\right)$ and MSC $\left(1 \times 10^{4}\right)$ in RPMI 1640 containing $10 \%$ FCS (PAA, Germany) for 5 days. Ovalbumin (OVA, $100 \mu \mathrm{g} / \mathrm{ml}$ ) protein (Hyglos, Germany) was added to the culture medium. OVA-specific proliferation was evaluated as a CFSE dilution by flow cytometry.

\section{Intracellular cytokine and Foxp3 staining}

For cytokine staining cells were stimulated for $6 \mathrm{~h}$ at $37^{\circ} \mathrm{C}$ with $50 \mathrm{ng} / \mathrm{ml}$ PMA (Sigma-Aldrich, Germany), $1 \mu \mathrm{g} / \mathrm{ml}$ Ionnomycin (Sigma-Aldrich, Germany) and $3 \mu \mathrm{g} / \mathrm{ml}$ brefeldin A (eBioscience, Germany) in RPMI with $10 \%$ FBS (PAA, Germany). For intracellular cytokine or Foxp3 staining samples were first stained for surface antigens, washed with PBS (PAN Biotech, Germany), and centrifuged for $5 \mathrm{~min}$ at RT and $400 \mathrm{~g}$. The cell pellets were vortexed for dissociation and incubated with fixation/ permeabilization buffer (BD, Germany) $20 \mathrm{~min}$ at RT. After washing twice with $2 \mathrm{ml}$ of permeabilization/washing buffer (BD, Germany) the cells were resuspended in $100 \mu \mathrm{l}$ permeabilization buffer. Intracellular mAbs (IFN- $\gamma$, IL-4, IL-10, IL-17 from Biolegend, Germany; Foxp3, eBioscience, Germany) or isotype controls were added at the recommended concentrations and incubated $30 \mathrm{~min}$ at RT. Cells were washed two times with permeabilization/washing buffer and immediately analyzed by flow cytometry. The number of acquired events was $\geq 500,000$.

\section{Respiratory leukocyte subset discrimination}

The gating strategy has been described recently with minor modifications [23]. Briefly, out of the $\mathrm{CD} 45^{+}$cells, neutrophils were identified by GR $1{ }^{\text {bright }} \mathrm{CD} 11 \mathrm{~b}^{\text {bright }}$ expression. Subsequently, out of the neutrophil negative fraction, macrophages were identified as Siglec $\mathrm{F}^{++} / \mathrm{CD} 11 \mathrm{c}$ positive cells. DC were identified according to $\mathrm{CD} 11 \mathrm{c}^{+}$Siglec- $\mathrm{F}^{\text {neg }}$ NK1.1 ${ }^{\text {neg }}$ expression to exclude autofluorescent macrophages and NK cells. Then they were further dissected into plasmacytoid DC $\left(120 \mathrm{~g}^{+} \mathrm{CD} 11 \mathrm{~b}^{\text {neg }}\right)$ and after MHC-class $\mathrm{II}^{+}$gating into $\mathrm{CD} 103 \mathrm{DC}\left(\mathrm{CD} 103^{+} \mathrm{CD}_{11 \mathrm{~b}^{\text {neg }}}\right)$ and $\mathrm{CD} 11 \mathrm{~b}$ DC $\left(\mathrm{CD} 11 \mathrm{~b}^{+} \mathrm{CD} 103^{\text {neg }}\right) . \mathrm{CD}^{+}{ }^{+}$cells and $\mathrm{CD} 19^{+} \mathrm{B}$ cells were identified within the $\mathrm{CD} 45^{+} \mathrm{SSC}^{\text {low }}$ fraction. Out of the $\mathrm{CD}^{+}{ }^{+} \mathrm{T}$ cell fraction, $\mathrm{CD} 4^{+}$and $\mathrm{CD} 8^{+} \mathrm{T}$ cells were identified on the basis of CD4 and CD8 expression, respectively. NK cells were identified as $\mathrm{CD} 3^{\text {neg }} \mathrm{NK} 1.1^{+}$cells and $\gamma \delta \mathrm{T}$ cells were identified as $\mathrm{CD}^{+} \gamma \delta \mathrm{TCR}^{+}$cells (Additional file 1: Figure S1). T regulatory cells were identified as $\mathrm{CD} 3^{+} \mathrm{CD} 4^{+} \mathrm{CD} 25^{+} \mathrm{Foxp}^{+}$cells.

\section{BAL protein and cytokine quantification}

Protein quantification was performed with Pierce BCA Protein Assay Kit (Thermo Scientific, Germany). Mouse TNF- $\alpha$, IL-10 and IL-12p70 were quantified by cytometric bead arrays according to the manufacturer's instructions (Flowcytomix, eBioscience, Germany.

\section{Statistical analyses}

Statistical analyses were performed using the GraphPad Prism software version 5.02 (Graphpad Software, Inc., USA). The significance of any differences between groups were analyzed by the one-way ANOVA and Tukey post-test for multiple comparisons. Survival curve comparison and analysis was performed using the logrank test. A $p$-value of $<0.05$ was considered statistically significant. 


\section{Results}

Prospective high-purity PaS MSC isolation and in vitro expansion

In the $\mathrm{BM}$ of $\mathrm{C} 57 \mathrm{BL} / 6$ mice less than $0.1 \%$ of nucleated cells exhibited the phenotype of $\mathrm{P} \alpha \mathrm{S}$ MSC (CD45 ${ }^{\text {neg }}$ TER119 ${ }^{\text {neg }} \mathrm{CD} 140 \mathrm{a}^{+} \mathrm{SCA}-1^{+}$; Fig. 1a). P $\alpha \mathrm{S}$ MSC were purified via FACS sorting to a final purity of $>98 \%$ (Fig. 1b). Due to the high purity sorting procedure, the cell yield per mouse was low (range 180-400 PaS MSC per mouse). $\mathrm{P} \alpha \mathrm{S}$ MSC were then grown in vitro for 20-40 days (Fig. 1c). They exhibited a spindle-shaped morphology (Fig. 1d) and inhibited T-cell proliferation in an antigen-specific $\mathrm{T}$ proliferation assay with OVA-pulsed DC and transgenic OVA-TCR specific CD4+ responder T cells (Fig. 1e). P $\alpha$ S MSC retained their expression of CD140a (PDFGR $\alpha$ ) and SCA-1 (Fig. 1f). In addition, extended phenotypic analysis of expanded $\mathrm{P} \alpha \mathrm{S}$ MSC revealed homogenous expression of the MSC markers CD29, CD49e, CD90 and CD105 and the absence of the HSC/endothelial marker CD34, the leukocyte markers CD45, CD49b, the endothelial markers CD309, Tie-2 and the erythroid marker TER119 (Fig. 1f).

\section{PaS MSC inhibit acute alveolitis and lung injury after $K$. pneumoniae infection}

At $4 \mathrm{~h}$ after induction of respiratory $K$. pneumoniae infection, the animals intratracheally received $1 \times 10^{6} \mathrm{P} \alpha \mathrm{S}$ MSC that were resuspended in $\mathrm{NaCl}$ or a negative control $(\mathrm{NaCl})$. Irrespective of $\mathrm{P} \alpha \mathrm{S} \mathrm{MSC}$ treatment, the infected animals exhibited a marked reduction of body weight within $48 \mathrm{~h}$ p.i. representing an indirect sign of disease (Fig. 2a). Dissection of major alveolar leukocyte subsets indicated a significant inhibition of acute alveolitis by $\mathrm{P} \alpha \mathrm{S}$ MSC treatment (Fig. 2b-e). Furthermore,

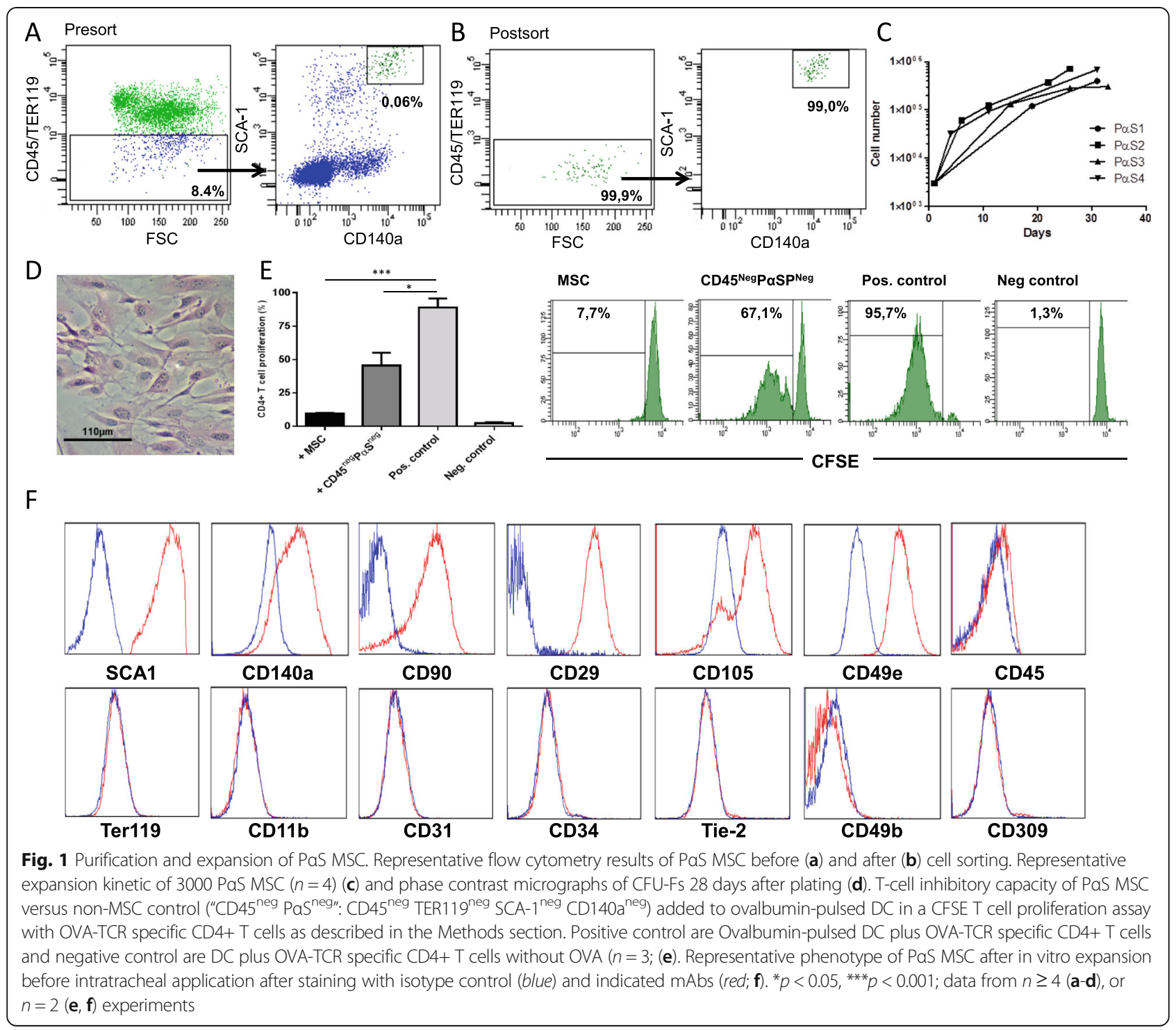




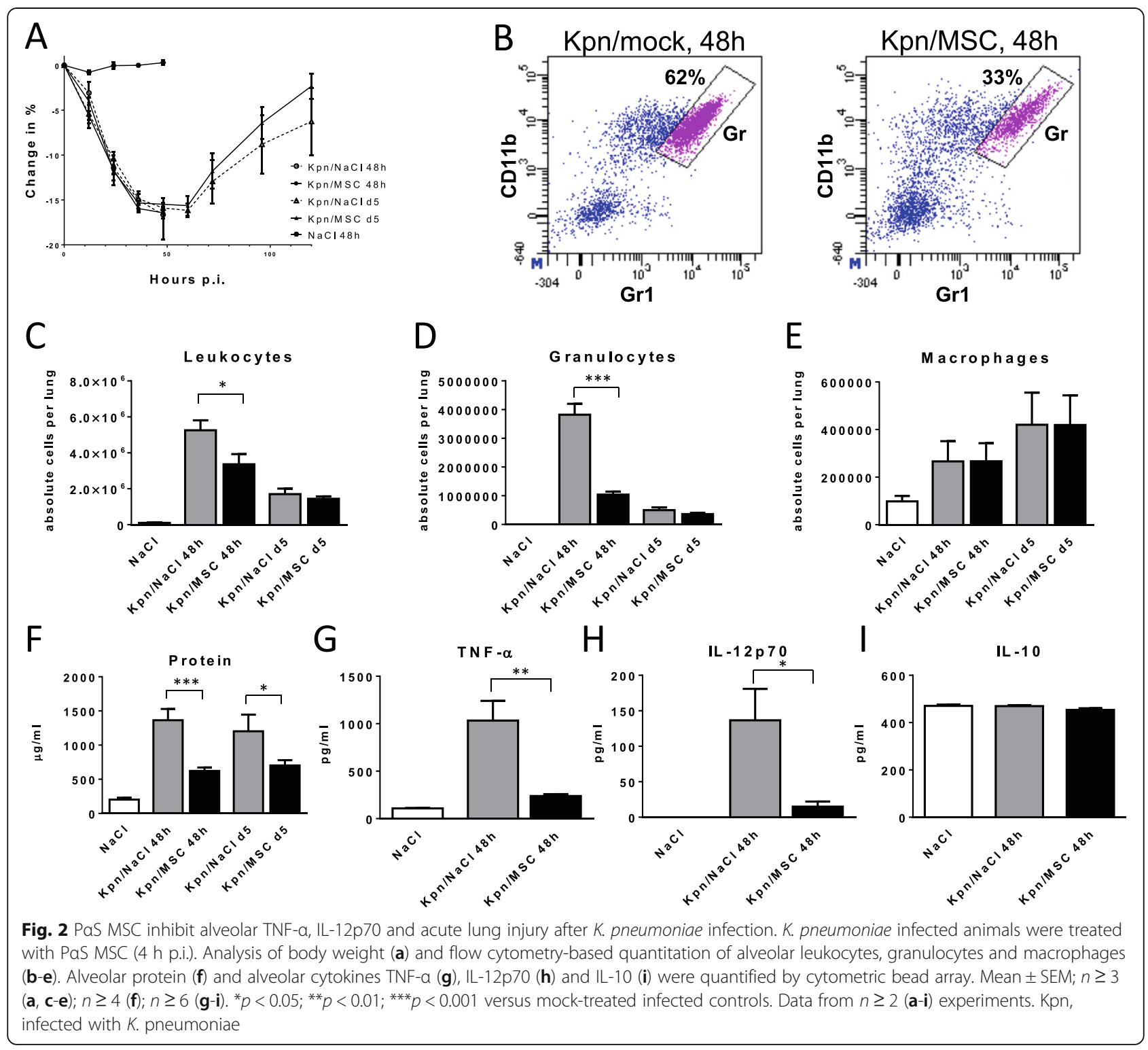

analysis of alveolar protein content as a measure of alveolar protein permeability and fluid clearance revealed that it was significantly reduced indicating less severe acute lung injury $(p<0.001,48 \mathrm{~h}$ p.i.; Fig. $2 \mathrm{f})$. Because the protein content represents a rather crude measurement of alveolar injury and inflammation we specifically determined the major pro-inflammatory cytokines TNF $\alpha$ and IL-12p70 and the immunoregulatory cytokine IL-10 (Fig. 2g-i). P $\alpha$ S MSC treatment significantly inhibited both alveolar TNF $\alpha(p<0.01)$ and IL-12p70 $(p<0.05)$ whereas IL-10 was unaffected. These data suggest that PoS MSC treatment inhibited $K$. pneumoniae-induced alveolar cellular inflammation, functional deterioration and pro-inflammatory cytokine production. In addition, histopathological analysis (Fig. 3) indicated severe suppurative and necrotizing pleuritis and steatitis admixed with myriads of bacteria in contrast to MSC-treated animals that did not display pleuritic, steatitis or bacteria on the lung surface or in the mediastinal fat tissue. Bacteriae were almost absent in MSC-treated animals but abundant in the mock-treated controls.

PaS MSC inhibit respiratory leukocytosis and DC infiltration after $K$. pneumoniae infection

In addition to the isolated alveolar compartment analysis we extended the analysis to all major leukocyte subsets in lung homogenates by using multiparameter flow cytometry during the acute $(48 \mathrm{~h}$ p.i) and postacute (d5 p.i) K. pneumoniae infection to better understand the modulation of the lung inflammatory process (Fig. 4). P $\alpha \mathrm{S}$ MSC treatment significantly suppressed granulocyte $(p<0.001,48 \mathrm{~h}$ p.i) and DC infiltration 


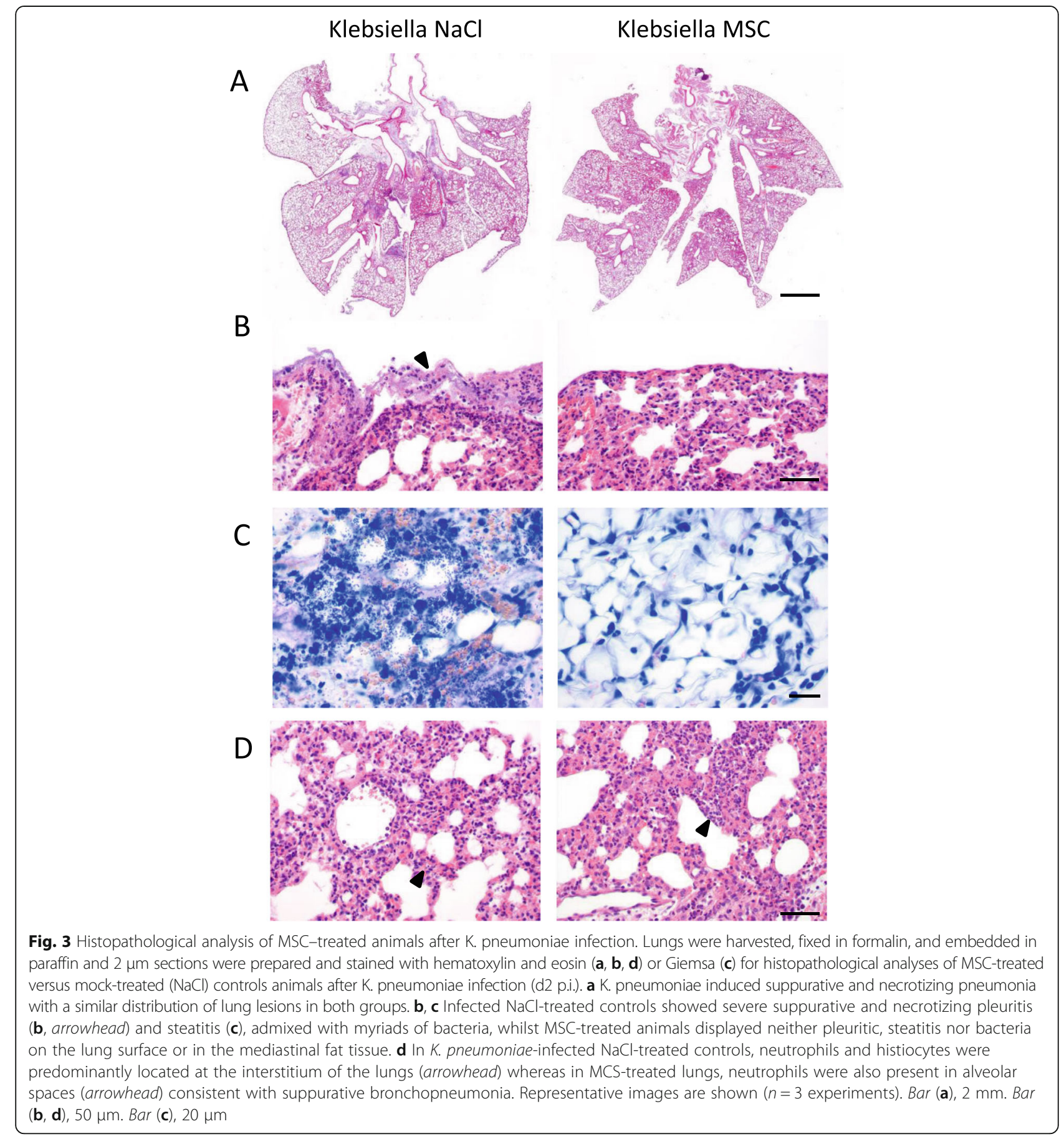

indicating reduced inflammation $(p<0.001, \mathrm{~d} 5 \mathrm{p.i})$. Dissection of respiratory DC subsets into plasmacytoid DC, $\mathrm{CD}_{103^{+}} \mathrm{DC}$ and $\mathrm{CD} 11 \mathrm{~b}^{+} \mathrm{DC}$ revealed a significant suppression of plasmacytoid DC infiltration early after infection $\left(p<0.001,48 \mathrm{~h}\right.$ p.i) and of plasmacytoid DC, CD103 ${ }^{+}$ DC and CD11 $\mathrm{b}^{+} \mathrm{DC}$ late after infection $(p<0.01, \mathrm{~d} 5$ p.i). In contrast, respiratory B lymphocytes and $\mathrm{CD} 4^{+}$and $\mathrm{CD} 8^{+} \mathrm{T}$ lymphocytes were not significantly affected. In addition, with respect to innate lymphocytes, P $\alpha \mathrm{S}$ MSC treatment significantly suppressed respiratory $\gamma \delta-\mathrm{TCR}^{+} \mathrm{T}$ cell numbers 48 h p.i. $(p<0.001)$ but not NK cells.

PaS MSC inhibit CD86 costimulatory molecule expression on lung $\mathrm{CD}_{103^{+}} \mathrm{DC}$ during acute $K$. pneumoniae infection Given the observation, that $\mathrm{P} \alpha \mathrm{S}$ MSC treatment significantly inhibited lung DC infiltration we questioned whether surface expression of the functionally relevant costimulatory molecule CD86, the immunoregulatory 


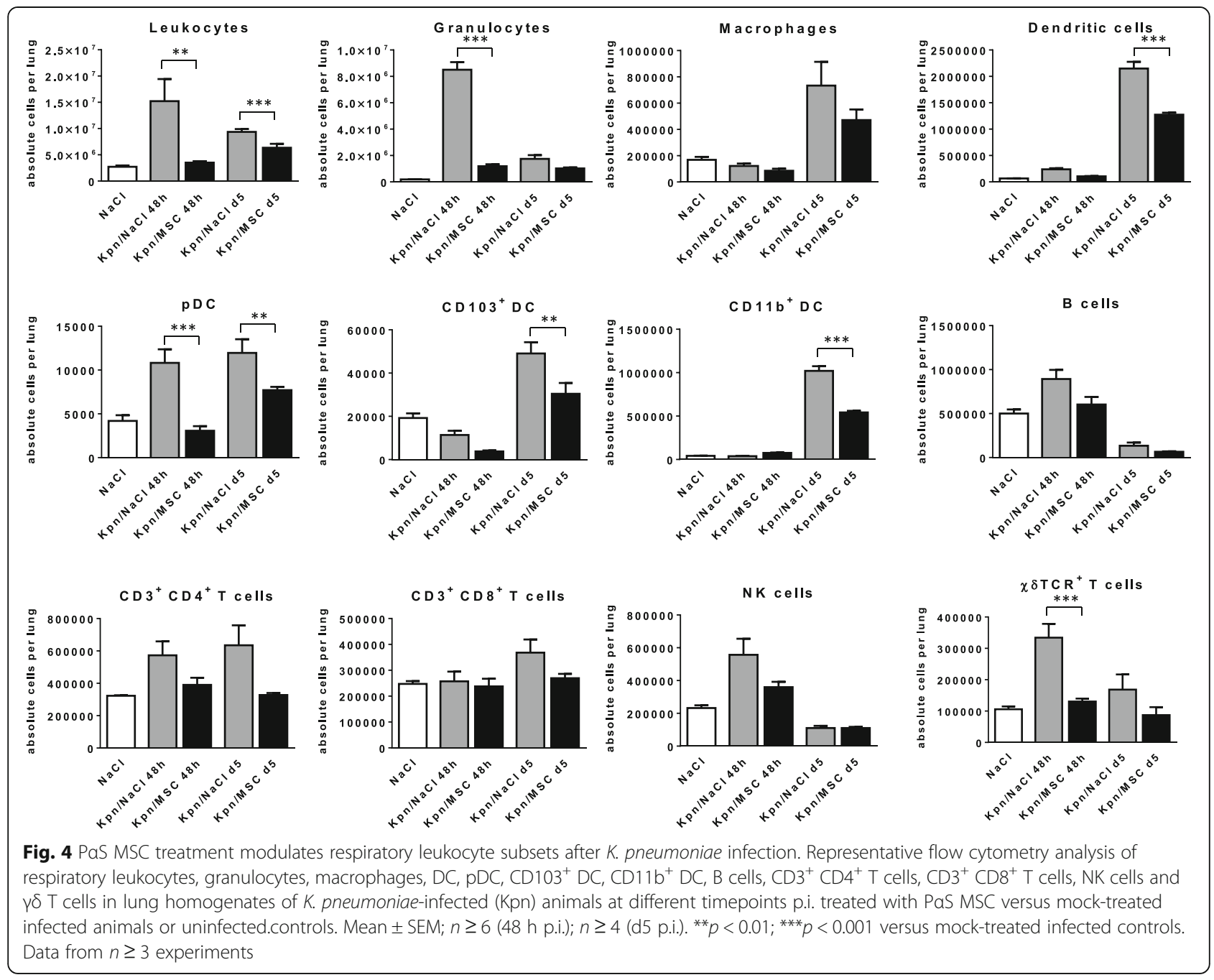

molecule PD-L1 (CD274) and MHC-class II were affected by P $\alpha$ S MSC treatment of lung DC subsets (Fig. 5a-b). These analyses revealed a significant suppression of CD86 expression on $\mathrm{CD}_{103^{+}} \mathrm{DC}$ early after infection $(p<0.001,48 \mathrm{~h}$ p.i.) in contrast to later time points $(\mathrm{d} 5$ p.i.)

\section{PaS MSC inhibit post-infectious expansion of lung pro-} inflammatory IFN- $\gamma^{+}$and IL- $17^{+} T$ cells without affecting respiratory $\mathrm{T}$ regulatory cells

The identification of reduced DC infiltration and impaired $\mathrm{CD}_{103^{+}} \mathrm{DC}$ costimulatory molecule expression raised the question whether $\mathrm{P} \alpha \mathrm{S}$ MSC treatment interfered also with the post-infectious expansion of polarized $\mathrm{T}$ cells (Fig. 6a-c). The results indicated that $\mathrm{P} \alpha \mathrm{S}$ MSC treatment significantly inhibited both the relative and absolute numbers of lung $\mathrm{CD} 4^{+} \mathrm{IFN}-\gamma^{+}$and $\mathrm{CD} 4^{+}$ IL- $17^{+} \mathrm{T}$ cells $\left(p<0.05\right.$, d5 p.i.) in contrast to IL- $4^{+}$, IL$10^{+}$and Foxp $3^{+} \mathrm{CD}_{2} 5^{+} \mathrm{CD}^{+} \mathrm{T}$ cells (Additional file 2: Figure S2). These experiments suggested that P $\alpha$ S MSC treatment modulated adaptive immunity by impairing pro-inflammatory IL-17 and IFN- $\gamma$ expressing $\mathrm{T}$ cell subsets.

\section{PaS MSC improve pneumonia survival and do not increase bacterial load}

$\mathrm{P} \alpha \mathrm{S}$ MSC treatment after respiratory $K$. pneumoniae infection resulted in significantly improved overall survival in comparison to mock-treated ( $\mathrm{NaCl}$ only) animals (Fig. 7a). To assess whether the positive results of $\mathrm{P} \alpha \mathrm{S}$ MSC may be related to an unspecific cellular effect we performed experiments with MLg fibroblasts instead of P $\alpha$ S MSC. Most MLg fibroblast-treated animals died within $24 \mathrm{~h}$ p.i. resulting in significantly reduced survival in comparison to both $\mathrm{P} \alpha \mathrm{S}$ MSC and $\mathrm{NaCl}$-only treated animals $(p<0.01$; Fig. 7a).

With respect to the markedly impaired respiratory inflammation and reduced numbers of pro-inflammatory T cells P $\alpha$ S MSC may exert immunosuppressive activity and might increase bacterial loads after infection. 


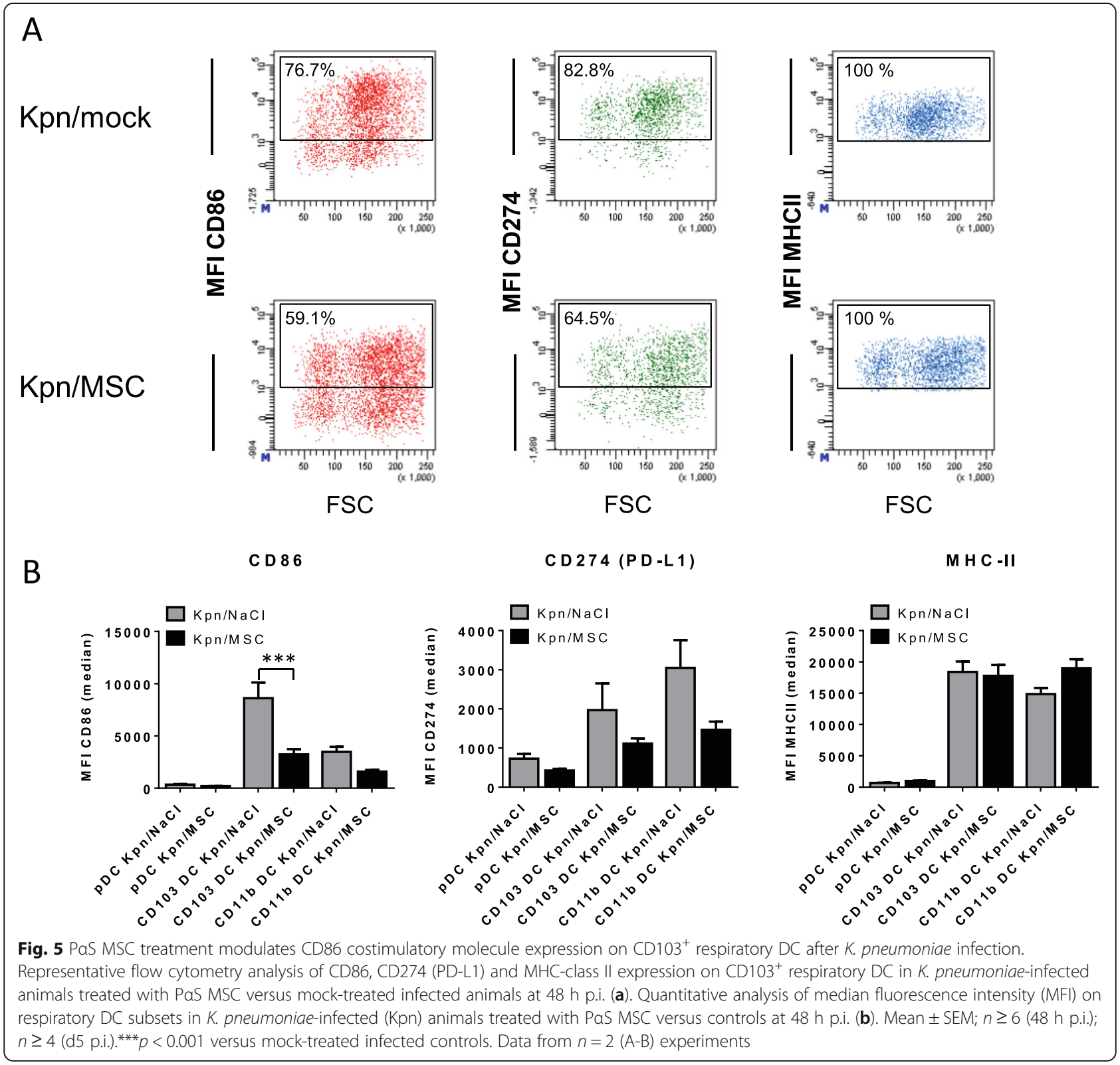

Accordingly, we determined the bacterial loads in lung homogenates and BAL at different time points after $K$. pneumoniae infection (Fig. 7b-c). The results consistently showed that P $\alpha$ S MSC treatment did not result in increased bacterial loads in lung homogenates or in BAL, indicating that $\mathrm{P} \alpha \mathrm{S}$ MSC are unlikely to impair antibacterial immunity.

\section{Discussion}

In this study we report on the immunomodulatory capacity of prospectively defined MSC in a preclinical mouse model of acute bacterial pneumonia. Many studies have highlighted the immunomodulatory capacity of MSC but most, if not all studies have used heterogeneous mixtures of starting cells for the in vitro expansion of MSC. Recently Matsuzaki et al. has identified a BM-derived MSC subset, expressing PDGFR $\alpha$ and Sca-1, so-called P $\alpha$ S cells, that are highly enriched for CFU-Fs with differentiation potential [7]. Here we have demonstrated that these prospectively defined P $\alpha$ S cells exhibited marked immunomodulatory capacity in vivo. The prospective identification of MSC based on surface markers facilitates the development of standardized protocols and additionally improves the comparability of scientific studies $[4,8]$. In accordance with Morikawa et al., we have found that cultured $\mathrm{P} \alpha \mathrm{S}$ cells uniformly expressed conventional MSC markers CD29, CD49e and SCA-1 and were positive for CD90 and CD105 [7]. 


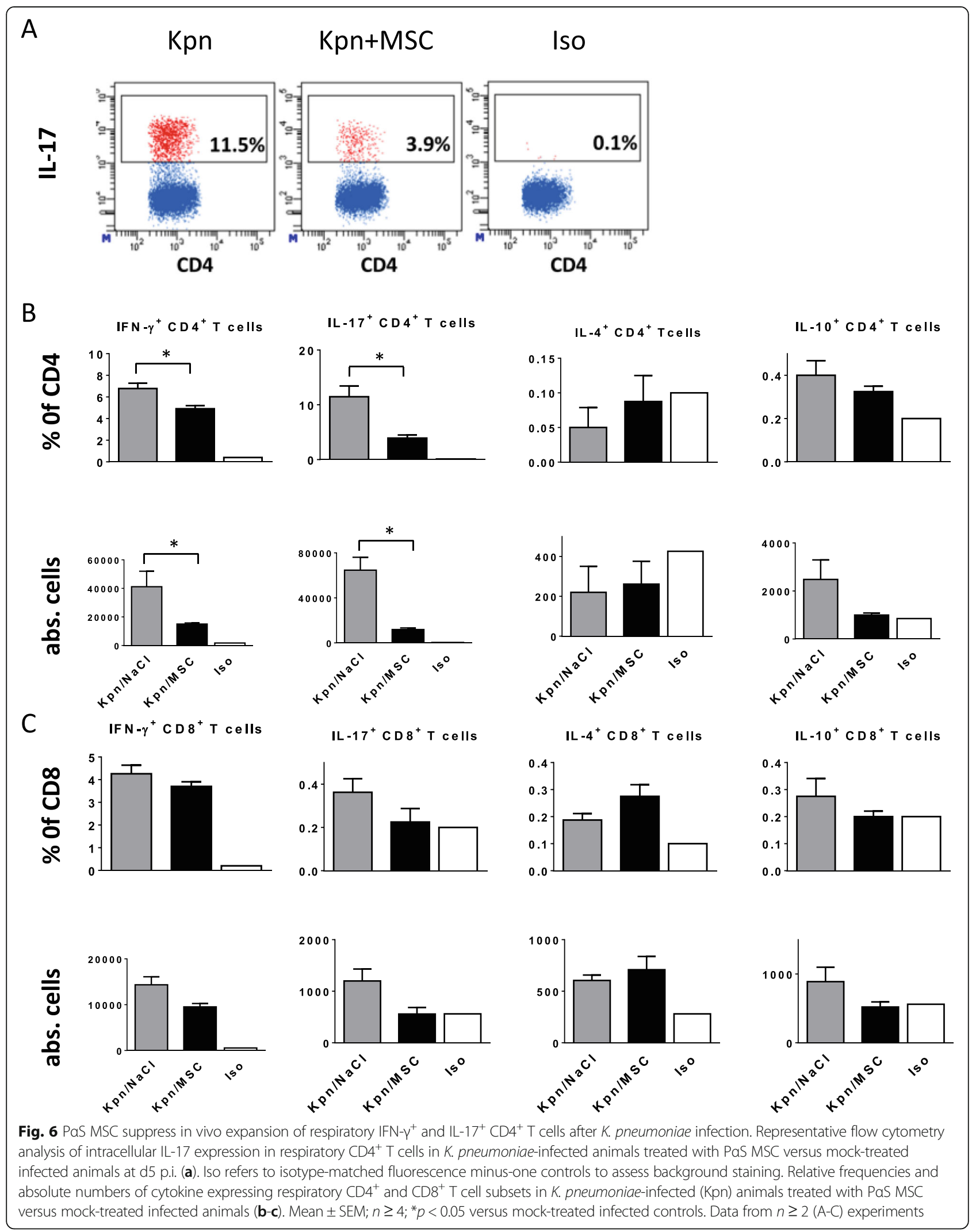



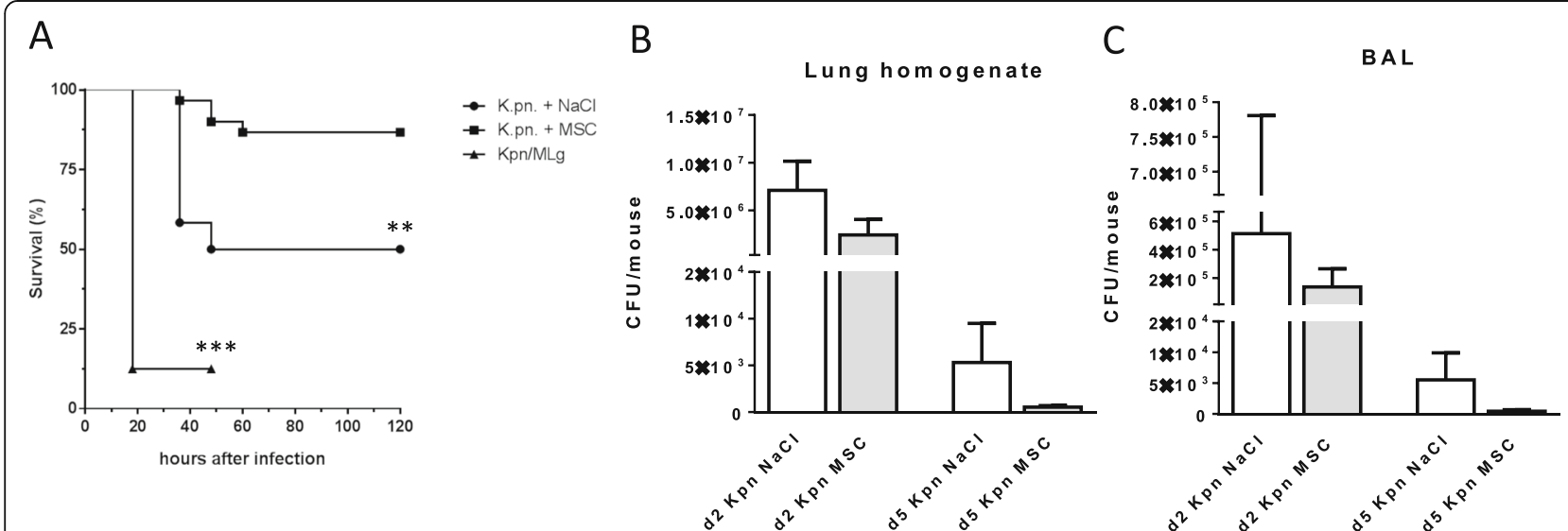

Fig. 7 PaS MSC improve survival and do not impair bacterial clearance after K. pneumoniae infection. Survival of K. pneumoniae-infected animals treated with $\mathrm{NaCl}$, PaS MSC or MLg fibroblasts (a). Bacterial load (colony forming units, CFU) of lung homogenate (b) and BAL (c) of $K$. pneumoniae-infected (Kpn) animals treated with PaS MSC or NaCl at $48 \mathrm{~h}$ and d5 p.i. (a) $n \geq 8,(\mathbf{b}, \mathbf{c})$ mean \pm SEM; $n \geq 3$ per group. ${ }^{* *} p<0.01$, ${ }^{* * *} p<0.001$ versus mock-treated infected controls. Data from $n \geq 2$ (A-C) experiments

Our results using prospectively defined MSC showed that expanded $\mathrm{P} \alpha \mathrm{S}$ cells effectively suppressed acute lung injury and acute alveolitis caused by respiratory K. pneumoniae. We selected a Klebsiella species as the pathogen because they represent an important group of bacteria that causes life threatening nosocomial infections [28]. Furthermore, multidrug resistant Klebsiella strains are of increasing clinical relevance worldwide due to limited treatment options [29]. We showed that PoS MSC treatment significantly inhibited alveolar protein leakage, granulocytosis and TNF- $\alpha$ production indicating a marked in vivo anti-inflammatory capacity. Furthermore, P $\alpha$ S MSC treatment inhibited not only acute lung injury but additionally suppressed expansion of pro-inflammatory $\mathrm{T}$ helper subsets expressing IL-17 and IFN- $\gamma$ in the postacute pneumonia phase. Our flow cytometry analysis of respiratory DC subsets provides a rationale for understanding the marked inhibition of IL-17 and IFN- $\gamma$ expressing $\mathrm{T}$ helper cells. Our results suggested that $\mathrm{P} \alpha \mathrm{S}$ MSC treatment effectively inhibited accumulation and CD86 upregulation on respiratory $\mathrm{CD}_{103}{ }^{+}$DC. Different reports have highlighted the critical role of $\mathrm{CD}_{103^{+}} \mathrm{DC}$ for the expansion of IL-17 and IFN- $\gamma$ driven T effector cell responses [30, 31].

Various studies have investigated the effect of MSC in models of LPS- or bleomycin-induced lung injury and have reported significant amelioration after lung injury $[18,32,33]$ as well as a significant survival benefit in MSC-treated animals [18, 33].

Only a few studies have investigated the therapeutic activity of MSC in pneumonia models with live bacteria $[19,20,34]$. Gupta et al. and Kim et al. reported that intratracheal MSC treatment improved survival and bacterial clearance in murine Escherichia coli pneumonia $[19,20]$. Here we have extended these findings by using prospectively defined $\mathrm{P} \alpha \mathrm{S}$ MSC in a $K$. pneumoniainfected animal model. Independent animal models employing live bacteria are of clinical relevance because there may be concerns that "immunosuppressive" MSC might promote bacterial growth due to an impairment of host defences. Our results using prospectively defined MSC are in agreement with other data indicating that intratracheal MSC therapy during infectious pneumonia promotes rather than inhibits bacterial clearance [19]. Matthay et al. has suggested that the antibacterial effect of MSC are due to the upregulation of the antibacterial proteins lipocalin 2 and LL37 [19, 35]. Recent evidence by Devaney et al. further supports this finding in a rat $\mathrm{E}$. coli pneumonia model. In their study, MSC-treatment significantly reduced acute lung injury, improved overall survival and decreased lung bacterial load. With respect to the potential anti-bacterial activity of MSC they reported enhanced macrophage phagocytic capacity and increased lung and systemic concentrations of the antimicrobial peptide LL37 in MSC-treated animals [34]. In agreement with these findings, our histopathological analyses indicated a strikingly reduced number of bacteria in the lungs of MSC-treated animals. However, mean values of bacterial loads were decreased in MSCtreated animals at $\mathrm{d} 2$ and $\mathrm{d} 5$ p.i. but these differences were statistically not significant due to the inter-individual variation. One may speculate that the antibacterial activity of MSC may play a key role in models with live bacteria. With respect to the immunomodulatory activity of MSC, several studies using different models have reported that MSC induced increased levels of IL-10 or Foxp3+ regulatory $\mathrm{T}$ cells $[18,36,37]$. However, in our study both IL-10 production as well as Foxp3+ CD4+ regulatory $\mathrm{T}$ cell frequencies were unaffected after MSC-therapy. Recently, Bustos et al. reported that pre-activation of human MSC 
with serum from patients with ARDS markedly increased their therapeutic capacity in a murine pneumonia model concomitant with increased IL-10 and IL-1 receptor antagonist levels [38]. Therefore, different levels of MSC pre-activation in different animal models may impact on their immunomodulatory capacity. With respect to the immunosuppressive capacity of MSC we observed significantly reduced CD86 surface expression on lung CD103+ DC in MSC-treated animals early after infection. CD86 represents a major $\mathrm{T}$ cell costimulatory molecule that is critically involved in T cell activation [39]. However, CD86 suppression was not significantly suppressed on CD11b + DC which may be related to different costimulatory molecule expression kinetics or differential migratory kinetics of CD11b + DC into inflamed tissue areas.

In summary, we have investigated the in vivo immunomodulatory capacity of prospectively defined, purified $\mathrm{P} \alpha \mathrm{S}$ MSC in a clinically relevant $K$. pneumoniae model. $\mathrm{P} \alpha \mathrm{S}$ MSC efficiently suppressed acute lung injury and promoted overall pneumonia survival. Flow cytometry analysis revealed impaired lung DC infiltration and $\mathrm{CD}_{103}{ }^{+} \mathrm{DC}$ maturation representing known key drivers of $\mathrm{T}$ cell-mediated inflammation, which provided a rationale for the sustained anti-inflammatory effects of MSC therapy. These findings support the potential of using prospectively defined MSC-based therapies for patients with acute bacterial pneumonia and provide new insight into the immunomodulatory capacity of $\mathrm{P} \alpha \mathrm{S}$ cells.

\section{Conclusions}

This experimental animal study has analyzed the in vivo immunomodulatory activity of prospectively defined MSC in acute bacterial pneumonia. In most published studies, MSC have been retrospectively defined based on their plastic adherent properties leading to heterogeneous cell populations. Our results indicate that intratracheal application of MSC effectively inhibit K.pneumoniae-induced acute lung injury and respiratory inflammation and provide additional evidence for the therapeutic activity of MSC in bacterial pneumonia.

\section{Additional files}

Additional file 1: Figure S1. Gating strategy for the identification of respiratory leukocyte subsets. Respiratory leukocytes were identified using CD45 surface expression. Respiratory lymphocytes were identified according to low side scatter characteristics and subsequently discriminated into CD19+ B cells, NK1.1+ NK cells, CD3 + $\gamma \delta$ TCR+ gamma-delta T cells, CD3+ CD4+ T cells and CD3+ CD8+T cells. Granulocytes and alveolar macrophages were subsequently identified out of CD45+ leukocytes based on CD1 1b and GR-1 expression (granulocytes) and CD11c and Siglec F surface expression (alveolar macrophages). DC subsets were subsequently identified out of CD45+ leukocytes based on CD11c expression in SiglecF/NK1.1/Gr1 negative cells to exclude contamination by alveolar macrophages, NK cells and granulocytes. This CD11c positive fraction was further discriminated into CD103+ DC and CD11b DC based on MHC-class II, CD103 and CD11b expression as well as in pDC based on $120 \mathrm{~g} 8$ expression and absence of CD11b. Representative figure from $n>10$ experiments. (PDF $382 \mathrm{~kb}$ )

Additional file 2: Figure S2. Modulation of respiratory CD4+CD25+ Foxp3+ regulatory T cells after PaS MSC treatment. Representative flow cytometry analysis of CD4+ CD25+ Foxp3+ regulatory T cells in $\mathrm{K}$. pneumoniae-infected animals treated with PaS MSC versus mock-treated infected animals (A, d5 p.i.). Iso refers to isotype-matched fluorescence minus-one controls to assess background staining. The frequency in \% refers to the frequency of CD4+ CD25+ Foxp3+ T cells among all CD4+ T cells. Relative frequencies and absolute numbers of respiratory CD4+ CD25+ Foxp3+ regulatory T cells in K. pneumoniae-infected (Kpn) animals treated with PaS MSC versus mock-treated infected animals (B). Mean \pm $\mathrm{SEM} ; n \geq 4$. Data from $n=2$ (A-B) experiments. (PDF $238 \mathrm{~kb}$ )

\section{Abbreviations}

ATCC: American type culture collection; BM: Bone marrow; BAL: Bronchoalveolar lavages; CFU-F: Colony-forming unit-fibroblasts; DC: Dendritic cells; HSC: Hematopoietic stem cells; K. pneumoniae: Klebsiella pneumoniae; MSC: Mesenchymal stem cells; MLg: Mouse lung fibroblasts; PaS: PDFGRa + SCA1+ CD45- TER119-.

\section{Competing interests}

The authors declare that they have no competing interests.

\section{Authors' contributions}

$\mathrm{HH}$ designed the research, analyzed and interpreted data and wrote the manuscript; AL, PK, IS, SK, KD, AG and NB performed research, analyzed and interpreted data; $\mathrm{MH}, \mathrm{GB}$ and $\mathrm{CB}$ interpreted data and critically read the manuscript. All authors read and approved the final manuscript.

\section{Acknowledgments}

We thank Andreas Wachtendorf for excellent technical assistance. The work was supported by the following grants and institutions: SFB Transregio 84, Project B3 (HH), University Gießen and Marburg Lung Center (UGMLC), Excellence Cluster Cardiopulmonary System (ECCPS).

\section{Author details}

${ }^{1}$ Institute for Clinical Immunology and Transfusion Medicine, Universities of Giessen and Marburg Lung Center (UGMLC), Member of the German Center for Lung Research (DZL), University Hospital Giessen und Marburg, Justus-Liebig-University Giessen, Langhansstr. 7, D-35390 Giessen, Germany. ${ }^{2}$ Department of Internal Medicine II, Universities of Giessen and Marburg Lung Center (UGMLC), Member of the German Center for Lung Research (DZL), University Hospital Giessen und Marburg, Justus-Liebig-University Giessen, Giessen, Germany. ${ }^{3}$ Department of Veterinary Pathology, Freie Universität Berlin, Robert-von-Ostertag-Str. 15, 14163, Berlin, Germany.

${ }^{4}$ Department of Hematology, Oncology and Immunology, Philipps University Marburg, University Hospital Giessen und Marburg, Marburg, Germany.

Received: 12 November 2014 Accepted: 2 October 2015 Published online: 06 October 2015

\section{References}

1. Chen BP, Galy AM, Fraser C, Hill B. Delineation of the human hematolymphoid system: potential applications of defined cell populations in cellular therapy. Immunol Rev. 1997;157:41-51.

2. Vogel W, Scheding S, Kanz L, Brugger W. Clinical applications of CD34(+) peripheral blood progenitor cells (PBPC). Stem Cells. 2000;18:87-92.

3. Kawabata Y, Hirokawa M, Komatsuda A, Sawada K. Clinical applications of CD34+ cell-selected peripheral blood stem cells. Ther Apher Dial. 2003;7:298-304

4. Mabuchi Y, Houlihan DD, Akazawa C, Okano H, Matsuzaki Y. Prospective isolation of murine and human bone marrow mesenchymal stem cells based on surface markers. Stem Cells Int. 2013;2013:507301.

5. Uccelli A, Moretta L, Pistoia V. Mesenchymal stem cells in health and disease. Nat Rev Immunol. 2008;8:726-36.

6. Dominici M, Le Blanc K, Mueller I, Slaper-Cortenbach I, Marini F, Krause D, et al. Minimal criteria for defining multipotent mesenchymal stromal cells. 
The international society for cellular therapy position statement. Cytotherapy. 2006;8:315-7.

7. Morikawa S, Mabuchi Y, Kubota Y, Nagai Y, Niibe K, Hiratsu E, et al. Prospective identification, isolation, and systemic transplantation of multipotent mesenchymal stem cells in murine bone marrow. J Exp Med. 2009:206:2483-96.

8. Houlihan DD, Mabuchi Y, Morikawa S, Niibe K, Araki D, Suzuki S, et al. Isolation of mouse mesenchymal stem cells on the basis of expression of Sca-1 and PDGFR-alpha. Nat Protoc. 2012;7:2103-11.

9. Mundra V, Gerling IC, Mahato RI. Mesenchymal stem cell-based therapy. Mol Pharm. 2013;10:77-89.

10. Shi Y, Su J, Roberts Al, Shou P, Rabson AB, Ren G. How mesenchymal stem cells interact with tissue immune responses. Trends Immunol. 2012;33:136-43.

11. Casado JG, Tarazona R, Sanchez-Margallo FM. NK and MSCs crosstalk: the sense of immunomodulation and their sensitivity. Stem Cell Rev. 2013;9:184-9.

12. Engela AU, Baan CC, Litjens NHR, Franquesa M, Betjes MGH, Weimar W, et al. Mesenchymal stem cells control alloreactive CD8(+) CD28(-) T cells. Clin Exp Immunol. 2013;174:449-58.

13. Dokic J, Tomic S, Markovic M, Milosavljevic P, Colic M. Mesenchymal stem cells from periapical lesions modulate differentiation and functional properties of monocyte-derived dendritic cells. Eur J Immunol. 2013;43:1862-72.

14. Chiesa S, Morbelli S, Morando S, Massollo M, Marini C, Bertoni A, et al. Mesenchymal stem cells impair in vivo T-cell priming by dendritic cells. Proc Natl Acad Sci U S A. 2011;108:17384-9.

15. Waterman RS, Tomchuck SL, Henkle SL, Betancourt AM. A new mesenchymal stem cell (MSC) paradigm: polarization into a pro-inflammatory MSC1 or an Immunosuppressive MSC2 phenotype. PLoS One. 2010;5:e10088.

16. Inoue S, Popp FC, Koehl GE, Piso P, Schlitt HJ, Geissler EK, et al. Immunomodulatory effects of mesenchymal stem cells in a rat organ transplant model. Transplantation. 2006;81:1589-95.

17. Sudres M, Norol F, Trenado A, Gregoire S, Charlotte F, Levacher B, et al. Bone marrow mesenchymal stem cells suppress lymphocyte proliferation in vitro but fail to prevent graft-versus-host disease in mice. J Immunol. 2006; 176:7761-7.

18. Gupta N, Su X, Popov B, Lee JW, Serikov V, Matthay MA. Intrapulmonary delivery of bone marrow-derived mesenchymal stem cells improves survival and attenuates endotoxin-induced acute lung injury in mice. J Immunol. 2007;179:1855-63.

19. Gupta N, Krasnodembskaya A, Kapetanaki M, Mouded M, Tan X, Serikov V, et al. Mesenchymal stem cells enhance survival and bacterial clearance in murine Escherichia coli pneumonia. Thorax. 2012;67:533-9.

20. Kim ES, Chang YS, Choi SJ, Kim JK, Yoo HS, Ahn SY, et al. Intratracheal transplantation of human umbilical cord blood-derived mesenchymal stem cells attenuates Escherichia coli-induced acute lung injury in mice. Respir Res. 2011;12:108.

21. Hackstein H, Hagel N, Knoche A, Kranz S, Lohmeyer J, von Wulffen W, et al. Skin TLR7 triggering promotes accumulation of respiratory dendritic cells and natural killer cells. PLoS One. 2012;7:e43320.

22. Hackstein H, Wachtendorf A, Kranz S, Lohmeyer J, Bein G, Baal N. Heterogeneity of respiratory dendritic cell subsets and lymphocyte populations in inbred mouse strains. Respir Res. 2012;13:94.

23. Hackstein H, Kranz S, Lippitsch A, Wachtendorf A, Kershaw O, Gruber AD, et al. Modulation of respiratory dendritic cells during Klebsiella pneumonia infection. Respir Res. 2013;14:91.

24. Nold P, Brendel C, Neubauer A, Bein G, Hackstein H. Good manufacturing practice-compliant animal-free expansion of human bone marrow derived mesenchymal stroma cells in a closed hollow-fiber-based bioreactor. Biochem Biophys Res Commun. 2013;430:325-30.

25. Maus $\mathrm{U}$, Herold $\mathrm{S}$, Muth H, Maus R, Ermert L, Ermert M, et al. Monocytes recruited into the alveolar air space of mice show a monocytic phenotype but upregulate CD14. Am J Physiol Lung Cell Mol Physiol. 2001;280:L58-68.

26. Schott C, Cai H, Parker L, Bateman KG, Caswell JL. Hydrogen peroxide production and free radical-mediated cell stress in Mycoplasma bovis pneumonia. J Comp Pathol. 2014;150:127-37.

27. Hackstein H, Morelli AE, Larregina AT, Ganster RW, Papworth GD, Logar AJ, et al. Aspirin inhibits in vitro maturation and in vivo immunostimulatory function of murine myeloid dendritic cells. J Immunol. 2001;166:7053-62.

28. Ahmad TA, El-Sayed LH, Haroun M, Hussein AA, El Ashry ESH. Development of immunization trials against Klebsiella pneumoniae. Vaccine. 2012;30:2411-20
29. Munoz-Price LS, Poirel L, Bonomo RA, Schwaber MJ, Daikos GL, Cormican M, et al. Clinical epidemiology of the global expansion of Klebsiella pneumoniae carbapenemases. Lancet Infect Dis. 2013;13:785-96.

30. Ivanov S, Fontaine J, Paget C, Macho Fernandez E, van Maele L, Renneson J, et al. Key role for respiratory CD103(+) dendritic cells, IFN-gamma, and IL-17 in protection against Streptococcus pneumoniae infection in response to alpha-galactosylceramide. J Infect Dis. 2012;206:723-34.

31. King IL, Kroenke MA, Segal BM. GM-CSF-dependent, CD103+ dermal dendritic cells play a critical role in Th effector cell differentiation after subcutaneous immunization. J Exp Med. 2010;207:953-61.

32. Ortiz LA, Gambelli F, McBride C, Gaupp D, Baddoo M, Kaminski N, et al. Mesenchymal stem cell engraftment in lung is enhanced in response to bleomycin exposure and ameliorates its fibrotic effects. Proc Natl Acad Sci U S A. 2003;100:8407-11.

33. Rojas M, Xu J, Woods CR, Mora AL, Spears W, Roman J, et al. Bone marrow-derived mesenchymal stem cells in repair of the injured lung. Am J Respir Cell Mol Biol. 2005;33:145-52.

34. Devaney J, Horie S, Masterson C, Elliman S, Barry F, O'Brien T, et al. Human mesenchymal stromal cells decrease the severity of acute lung injury induced by E. coli in the rat. Thorax. 2015;70:625-35.

35. Krasnodembskaya A, Song Y, Fang X, Gupta N, Serikov V, Lee J, et al. Antibacterial effect of human mesenchymal stem cells is mediated in part from secretion of the antimicrobial peptide LL-37. Stem Cells. 2010;28:2229-38.

36. Moghadasali R, Azarnia M, Hajinasrollah M, Arghani H, Nassiri SM, Molazem $M$, et al. Intra-renal arterial injection of autologous bone marrow mesenchymal stromal cells ameliorates cisplatin-induced acute kidney injury in a rhesus Macaque mulatta monkey model. Cytotherapy. 2014;16:734-49.

37. Luz-Crawford P, Kurte M, Bravo-Alegria J, Contreras R, Nova-Lamperti E, Tejedor G, et al. Mesenchymal stem cells generate a CD4 + CD25 + Foxp3+ regulatory $T$ cell population during the differentiation process of Th1 and Th17 cells. Stem Cell Res Ther. 2013;4:65.

38. Bustos ML, Huleihel L, Meyer EM, Donnenberg AD, Donnenberg VS, Sciurba JD, et al. Activation of human mesenchymal stem cells impacts their therapeutic abilities in lung injury by increasing interleukin (IL)-10 and IL-1RN levels. Stem Cells Transl Med. 2013;2:884-95.

39. Carreno BM, Collins M. The B7 family of ligands and its receptors: new pathways for costimulation and inhibition of immune responses. Annu Rev Immunol. 2002;20:29-53.

\section{Submit your next manuscript to BioMed Central and take full advantage of:}

- Convenient online submission

- Thorough peer review

- No space constraints or color figure charges

- Immediate publication on acceptance

- Inclusion in PubMed, CAS, Scopus and Google Scholar

- Research which is freely available for redistribution 